\title{
The Impact of Creativity and Intelligence on the Social Adaptation of the Students of the Faculty of Physical Education
}

\author{
Borys A. Yakymchuk ${ }^{1, *}$, Iryna P. Yakymchuk ${ }^{1}$, Iryna O. Vakhotska ${ }^{1}$, Irina V. Sundukova ${ }^{2}$ \\ and Yaroslava O. Lohvinova ${ }^{2}$
}

\author{
${ }^{1}$ Department of Psychology, Social and Psychological Education Faculty, Pavlo Tychyna Uman State \\ Pedagogical University, 2 Sadova str., Uman, 20300, Ukraine \\ ${ }^{2}$ Department of Theory and Methodology of Physical Education, Faculty of Physical Education, Volodymyr \\ Vynnychenko Central Ukrainian State Pedagogical University, 1, Shevchenko str., Kropivnitsky, 25006, \\ Ukraine
}

\begin{abstract}
In periods of social change, creativity is the leading resource for human adaptation. Therefore, in the learning process, it is important to provide for the development of creativity both as a professional skill and as a general life competence. This work aims to elucidate the features of the formation of creativity and intelligence of students in connection with their position in interpersonal relationships. We measured various creative abilities of 224 students of the Faculty of Physical Education (a set of tasks from the tests of creativity by Torrance and Guilford); general intelligence (Raven's Progressive matrices) and sociometric status (Moreno's method, the criteria of educational achievements, informal-emotional communication and sports team leadership were used). It is shown that in the learning process, students significantly increase the level of general intelligence, verbal and practical (everyday) creativity increases. The uneven dynamics of the manifestations of different types of creativity depending on the stage of learning was revealed: during periods of intense adaptation, a redistribution of cognitive efforts to achieve more significant and relevant goals was observed. Eight different types of combinations of creative abilities and general intelligence that determine the diversity of students' adaptation strategies have been identified. Direct correlations and nonlinear relationships between the severity of various cognitive abilities and sociometric status are described. The balance of intellectual and creative processes, their effective use in various situations of interpersonal interaction is the key to gaining social authority.
\end{abstract}

Keywords: Everyday creativity, verbal creativity, imaginative creativity, general intelligence, leadership, physical training.

\section{INTRODUCTION}

Almost 70 years have passed since J. P. Guilford [1] singled out divergent thinking "without boundaries" in the structure of the intelligence and made the problem of creativity (the ability to abandon stereotypical ways of thinking and generate new ideas) a priority of psychological science. Today, humanity has entered a new historical stage, when the meaning of creativity has changed - from intellectual privilege it has become a necessity, an important life competence. To survive, we must constantly master innovations, cope with unpredictable rapid changes, orientate ourselves in the absence of reference points. A creative approach is necessary both for adaptation of the individual and for the development of organizations, society as a whole. It is creative ideas born and embodied by creative people that provide a solution to complex scientific, technical, economic, social, cultural, spiritual, etc. problems; they push the limits of existing opportunities and move civilization forward.

*Address correspondence to this author at the Department of Psychology, Social and Psychological Education Faculty, Pavlo Tychyna Uman State Pedagogical University, 2 Sadova str., Uman, 20300, Ukraine;

Tel: ++380679474717; Fax: (04744) 3-45-82;

E-mail: borysyakymchuk@yahoo.com
The desire to understand and manage the creative process has initiated millions of studies around the world. Scholars study creativity as a cognitive process [2-5], as a creative product, an outstanding result in various fields of socially significant activity [6-8], as a component of giftedness [9, 10], as a personality trait [11-13]. Environmental factors that influence the formation and manifestation of creative abilities throughout life are of interest [14-16]. Many tools for diagnosing creative potential have been developed [1720]. A variety of methods of teaching children and adults creativity [21, 22]; recommendations for creating a stimulating environment $[23,24]$ were proposed.

Although psychology has made significant advances in understanding the nature of creativity, it still seems mysterious. A recent meta-analytical review by B. Hennessey and T. Amabile [25] showed an explosion of information, and literature has become more complex methodologically and theoretically. Scholars are concerned about the stunning pluralism of opinions and the lack of consensus in disciplinary approaches among professionals. An increase in the volume of publications and a variety of focuses led to a fragmentation of knowledge: "researchers in one subfield often seem unaware of work being done in 
another" [25, p. 590]. A variety of creative manifestations led to a well-founded proposal to distinguish between relatively rare Big creativity, which affects the life of the whole society, Pro-creativity as a professional skill, Little creativity in solving life problems, and also "mini-c" - creative processes associated with gaining new personal experience and knowledge [8].

One of the most controversial issues is still the relationship between the main cognitive abilities of a person: intelligence (as the ability to find a solution in situations where the correct answer is implied) and creativity as the ability to find many solutions in situations of uncertainty. Some authoritative scientists consider creativity a component of the structure of intelligence, the highest level of development of thinking $[3,18,26]$, while others consider them as separate abilities, the combination of which determines success in adaptation [11], the third point to partial correlations between these parameters [5]. The intellectual threshold theory explains: with IQ up to 115 120 points, intelligence and creativity form a single factor, but with a high IQ, creativity develops independently (that is, there can be highly intelligent people with low creativity, but a combination of low intelligence and developed creativity is impossible) [19].

Today, creativity and intelligence are in demand as the supra-professional competencies (Soft skills) that employers want to see in university graduates of any speciality. It is important to consider the use and development of these abilities in undergraduate programs. In terms of creativity, this is an urgent problem, since the traditional dominance of reproductive processes in the educational system obscures alternative cognitive abilities (as well as a wide range of other talents). To carry out reforms, fundamental research is needed to explain the relationship between intelligence and creativity among students, their impact on social adaptation, professional and life success.

The objective of this work is to find out the features of the formation of intelligence and creativity among students of the Faculty of Physical Education, as well as their relationship with the position in interpersonal relations.

Students specializing in Physical Education rarely find themselves in the focus of research of creative and intellectual processes. The results obtained will help to recognize different options of gifted students and create a stimulating environment for comfortable adaptation and effective development of abilities in teaching bachelors.

\section{METHODS}

\section{Research Design}

The study consisted of several stages that specified the goal:

1. Determining the dynamics of the development of abilities in the learning process: a comparison of the average indicators of creativity and general intelligence in students of 1, 2, 3 and 4 courses.

2. Clarification of the relationship between the individual components of creativity and intelligence among student-athletes (correlation and cluster analysis).

3. Finding out how intellectual and creative abilities determine leadership in interpersonal relationships and social adaptation of students (correlation analysis and distribution of percentages).

\section{Participants}

Undergraduate students of the Faculty of Physical Education were observed. There were 12 study groups with a total number of 224 people involved: $1^{\text {st }}$ year 45 people, $2^{\text {nd }}$ year -64 people, $3^{\text {rd }}$ year -57 people, $4^{\text {th }}$ year -58 people. A feature of the contingent was a more or less pronounced sports career and regular physical activity, $40-50 \%$ of the curriculum was sports training.

\section{Procedures and Interpretation}

Psychological diagnostics of three phenomena were carried out: intelligence, creativity and features of building interpersonal relationships. All measuring instruments were blank. Data were collected in a group in three stages:

1. Sociometry J. Moreno. Group members were asked to answer questions that reveal their sympathies in various aspects of interpersonal relations (the limit of choice was determined by the size of the study group: up to 16 people -3 choices, 17-21 people -4 choices, 22-27 people -5 choices, $27-32$ person - up to 6 choices). We 
used three simple sociometric criteria that reflect the students' real experience:

- $\quad$ Academic: Who of your groupmates would you ask to help you with a training project or preparation for classes if you need?

- Informal-emotional: Who of your groupmates would you address yourself for advice, support in a difficult personal situation?

- $\quad$ Sports-and-team: If your group had an important sports competition, who would be the best captain in the team?

Of all the measuring capabilities of sociometry, we were interested in the sociometric status - a measure that allows us to establish the relative authority of the group members and classify the person in the category of "leaders". In the calculations, a value is obtained in the range from 0 to 1 . The person receives the highest sociometric status when all members of the group choose him/her, and the lowest one - when everyone rejects him/her. When interpreting the sociometric status, we assigned the student to one of four categories: sociometric "stars" (group leaders), popular, less popular and isolated [27].

2. Raven Progressive Matrices (a standard black and white version for adults) were used to measure students' intellectual abilities. This is one of the most reliable methods representing the classical English school of the study of general intelligence, the G-factor: the ability to draw conclusions based on unstructured information (build cognitive schemes) and learn from our own experience [28]. Its advantage is versatility, the possibility of use in various linguistic, cultural and socio-economic groups. The methodology contains 60 tasks with increasing difficulty in identifying relationships between abstract figures. Each correct answer is estimated at 1 point, the sum of the points is converted to percentile norms.

The respondents performed the task in groups in the presence of the researcher, the time allocated for completion was limited to 20 minutes [29, 30]. It should be noted that J. Raven [29] does not recommend limiting completion time in intelligence tests to avoid discrimination against people with a slow thinking style. But an even stricter warning concerns the inadmissibility of using outdated criteria for interpretation: "the result by which a fifty-year-old respondent would be assigned to the $95^{\text {th }}$ percentile in 1942 would now only allow him/her to be assigned to the $25^{\text {th }}$ percentile" [28]. Since the test standards obtained on the basis of national sample in 2016 implied a limited testing time [30], we used the following procedure: after 20 minutes, students put a mark on the form with the answers, and then, if desired, everybody who did not have time to complete test to the end could finish it.

3. Diagnosis of creative abilities. To diagnose creativity, we used the tasks of the test battery of E. Torrens (TTCT, Torrance tests of creative thinking), which is considered the most reliable and valid tool to assess the creative potential of a person. The test was adopted and standardized based on a Russian-language sample of E. Tunik in 2006 [20]. The developers claim that each of the subtests is multifunctional and able to measure all the basic criteria of creative thinking: fluency - the ability to generate a large number of intelligent ideas; flexibility - the ability to apply a variety of strategies to solve problems, consider the available information from different points of view; originality - the ability to produce non-standard and unique ideas; elaboration - the ability to develop ideas in detail [19, 20]. We used the TTCT "Alternative Uses" verbal battery subtest, figurative tasks "Incomplete figures" and "Repeating circles". We complemented this set by the task from the classic test of creativity of J. Guilford "Making Phrases" [18]. This is a minimally sufficient set of tasks that allows assessing the ability to put forward ideas in different modalities.

Non-verbal (imaginative) creativity:

"Incomplete figures" - draw ten abstract lines imposing stable images.

"Repeating circles" - based on 30 identical circles, create as many intelligent images as possible.

Verbal creativity:

"Alternative Uses Task" - come up with interesting and non-obvious ways to use empty cardboard boxes.

"Making Phrases" - to come up with sentences of four words, each word begins with the indicated letter.

We took into account that for the manifestation of creative abilities, a friendly and free testing atmosphere 
is important $[31,32]$. The tasks were fulfilled without time limits (in general, the diagnosis took 40-55 minutes). They were offered on four separate forms so that the respondent fulfilled them in the order convenient for him/her. Before starting the diagnosis, a brainstorming session was conducted in the groups through the example of "Alternative Uses" test (to come up with ways to reuse plastic bottles), which helped students understand the meaning of the tasks and "enter" into creative activity.

E. Tunik [20] calculated age norms relative to total estimates of imaginative and verbal creativity using TTCT. But since we used only part of the subtests in the study, we could not use them. Adaptation and standardization of Guildford's test problems have not yet been carried out on Russian-language samples. In order to classify students as "highly creative" or "low creative", the results of descriptive statistics in the general sample were used: values included in the interval $\mathrm{M} \pm \mathrm{SD}$ were identified as "middle level"; results in excess of $M+S D$ were identified as "high level", results below M-SD were identified as "low level". The correlation of different criteria of creativity, as well as similar variables in verbal and non-verbal tasks, allows judging about the individual structure of the creative abilities of students.

Diagnostics of students' intelligence and creativity took place on different days for one week to avoid the sequence effect, when the previous fulfilment of creativity tests reduces the efficiency of solving intellectual problems (hypothetically, the opposite effect is also possible) [33, 34].

\section{Ethical Considerations}

The participation of students in the study was exclusively voluntary. All participants completed the consent form and received guarantees that the test result obtained will be known only to researchers and will not affect their semester or course grades in any way.

\section{Data Analysis}

A comparative analysis of the parameters was carried out at different training courses (single-factor ANOVA Analysis of Variance). Cluster analysis was used to single out typological groups with a different combination of cognitive abilities. Correlation analysis demonstrated the structure of the relationships between the measured variables. The calculations were performed using SPSS 16.0 software. To identify non-linear relationships, we conducted a frequency analysis - manually calculated and compared the percentage of students of different categories.

\section{RESULTS}

The total number of study participants was 224 people, among them $56 \%$ were men and $44 \%$ were women. Students age - from 16 to 25 years (average age $=19.3$ ). $73.7 \%$ of respondents have experience in participating in regional, national and international competitions, of which 21 people ( $9.2 \%$ of the sample) were awarded high sports awards and titles. The results obtained reflect the characteristics of such categories of students.

\section{The Dynamics of the Development of Cognitive Abilities during Training}

Most students of the Faculty of Physical Education have a level of general intelligence in the medium-high range. For senior students, the average number of correct answers in the Raven test increases slightly, and the data spread decreases (Means and Standard Deviations are presented in Table 1).

A similar dynamic was also found with respect to the results of verbal creative tests - at each year there is an increase in fluency, flexibility and originality of ideas for the unusual use of objects. The development of the ability to make phrases and sentences according to a given pattern is most pronounced (the significance of the differences is 0.002). In this case, we observe the largest data spread; sportsmen students vary greatly in terms of vocabulary and verbal creativity.

Non-verbal tasks generally given to students of the Faculty of Physical Education are easier than verbal ones. In the subtest "Incomplete figures", the highest values of flexibility and originality are shown in the third year. These tasks make the respondents want to complete them in the simplest way according to the laws of the gestalt - to create an original drawing, the subject must refrain from this primary impulse. In the year of graduation, the freedom of putting forward ideas grows, but their quality somewhat decreases. Possibly, the increased workload and the situation of work stress cause the need for saving cognitive efforts. This assumption is confirmed by the results of the "Repeating circles" subtest: $4^{\text {th }}$-year students demonstrate the highest productivity, but the medium quality (flexibility, originality and elaboration) of solutions. Thus, the task is formally fulfilled, although 
Table 1: Results of Diagnosing General Intelligence and Creativity in Students of the Faculty of Physical Education, M $\pm S D$

\begin{tabular}{|c|c|c|c|c|c|}
\hline Measures of cognitive abilities & $\begin{array}{l}1^{\text {st }} \text { year } \\
(N=45)\end{array}$ & $\begin{array}{l}2^{\text {nd }} \text { year } \\
(N=64)\end{array}$ & $\begin{array}{l}3^{\text {rd }} \text { year } \\
(N=57)\end{array}$ & $\begin{array}{l}4^{\text {th }} \text { year } \\
(N=58)\end{array}$ & $\begin{array}{c}\text { ANOVA: } \\
\text { Sig. }\end{array}$ \\
\hline $\begin{array}{l}\text { General intelligence } \\
\text { Raven's progressive matrices, } \\
\text { number of correct answers }\end{array}$ & $40.7 \pm 10.5$ & $41.4 \pm 9.8$ & $44.9 \pm 8.6$ & $45.5 \pm 8.1$ & 0.041 \\
\hline \multicolumn{6}{|l|}{ Non-verbal (imaginative) creativity } \\
\hline $\begin{array}{l}\text { Incomplete figures: } \\
\qquad \begin{array}{r}\text { fluency } \\
\text { flexibility } \\
\text { originality } \\
\text { elaboration }\end{array}\end{array}$ & $\begin{array}{l}9.71 \pm 0.93 \\
2.23 \pm 0.19 \\
4.56 \pm 0.25 \\
5.45 \pm 2.24\end{array}$ & $\begin{array}{l}9.88 \pm 0.85 \\
2.45 \pm 0.27 \\
5.05 \pm 0.37 \\
5.16 \pm 2.78\end{array}$ & $\begin{array}{l}9.64 \pm 0.95 \\
3.06 \pm 0.25 \\
5.65 \pm 0.34 \\
6.08 \pm 3.03\end{array}$ & $\begin{array}{l}9.96 \pm 0.13 \\
2.18 \pm 0.25 \\
4.66 \pm 0.27 \\
5.43 \pm 3.15\end{array}$ & $\begin{array}{l}0.745 \\
0.017 \\
0.226 \\
0.452\end{array}$ \\
\hline $\begin{array}{l}\text { Repeating circles: } \\
\qquad \begin{array}{r}\text { fluency } \\
\text { flexibility } \\
\text { originality } \\
\text { elaboration }\end{array}\end{array}$ & $\begin{array}{l}24.5 \pm 5.4 \\
7.5 \pm 0.96 \\
12.6 \pm 3.9 \\
\mathbf{3 3 . 5} \pm 8.1\end{array}$ & $\begin{array}{l}22.6 \pm 6.1 \\
7.1 \pm 0.96 \\
11.0 \pm 2.8 \\
29.6 \pm 7.2\end{array}$ & $\begin{array}{l}23.4 \pm 5.9 \\
7.8 \pm 1.01 \\
14.6 \pm 3.3 \\
31.4 \pm 9.8\end{array}$ & $\begin{array}{c}25.6 \pm 3.6 \\
7.3 \pm 1.12 \\
12.5 \pm 2.9 \\
30.6 \pm 10.2\end{array}$ & $\begin{array}{l}0.435 \\
0.758 \\
0.036 \\
0.086\end{array}$ \\
\hline Verbal creativity & & & & & \\
\hline $\begin{array}{l}\text { Alternative Uses: } \\
\qquad \begin{aligned} \text { fluency } \\
\text { flexibility } \\
\text { originality }\end{aligned}\end{array}$ & $\begin{array}{l}10.4 \pm 3.2 \\
4.4 \pm 1.6 \\
4.0 \pm 2.6\end{array}$ & $\begin{array}{l}10.9 \pm 3.1 \\
4.6 \pm 1.7 \\
5.1 \pm 2.2\end{array}$ & $\begin{array}{l}11.0 \pm 2.7 \\
5.2 \pm 1.5 \\
5.1 \pm 2.0\end{array}$ & $\begin{array}{c}\mathbf{1 2 . 1} \pm 2.4 \\
\mathbf{5 . 5} \pm 1.1 \\
\mathbf{5 . 6} \pm 2.4\end{array}$ & $\begin{array}{l}\mathbf{0 . 0 5 3} \\
0.099 \\
\mathbf{0 . 0 2 3}\end{array}$ \\
\hline $\begin{array}{l}\text { Making Phrases: } \\
\\
\text { fluency }\end{array}$ & $2.9 \pm 3.5$ & $3.4 \pm 3.5$ & $4.1 \pm 3.6$ & $5.5 \pm 4.2$ & 0.002 \\
\hline
\end{tabular}

Note: the calculated value of Sig. $\leq 0.05$ confirms the difference in the mean values and variances in the compared groups; the highest, peak indicators in each data series are bold.

thinking remains rigid. But in more familiar situations, such as solving intellectual and verbal tasks, graduates demonstrate a significant advantage.

In general, the most striking manifestations of nonverbal creativity are observed in the $3^{\text {rd }}$ year, and verbal creativity - in the $4^{\text {th }}$ year.

\section{Correlation of Indicators of Creativity and Intelligence}

Correlation analysis showed that all parameters of creativity are interconnected by strong positive relationships. The nature of the relationships between the indicators of the creative test and general intelligence is reflected in Figure $\mathbf{1}$ and Table 2.

Cluster 2 is quite common because general intelligence is usually associated with a rich vocabulary, speed and flexibility of thinking.

Based on the significance of Cluster 4 (15\% students with high rates of fluency and originality in the test "Alternative uses"), we further consider it as a separate, specific component of creativity.
The uneven development of creativity (for example, high productivity with low originality and elaboration of answers) was found in $9 \%$. Previously, such cases have not been described in the literature; they require further study.

The described combination of abilities determines a wide range of response methods in a different life, study and professional situations. To understand how this affects leadership in interpersonal interaction, we calculated the average indicators of sociometric statuses in clusters - see Table 3.

We see that the selected clusters determine the specifics of social adaptation. So, comprehensively gifted students (Cluster1) have the most pronounced authority in the academic field; in the field of informal personal communication - students with strong verbal creativity (clusters 2 and 4 ) are most successful, while intellectuals with low creativity (cluster 3 ) have little chance of leading a sports team. The data obtained are of practical value for team building in organizations. 


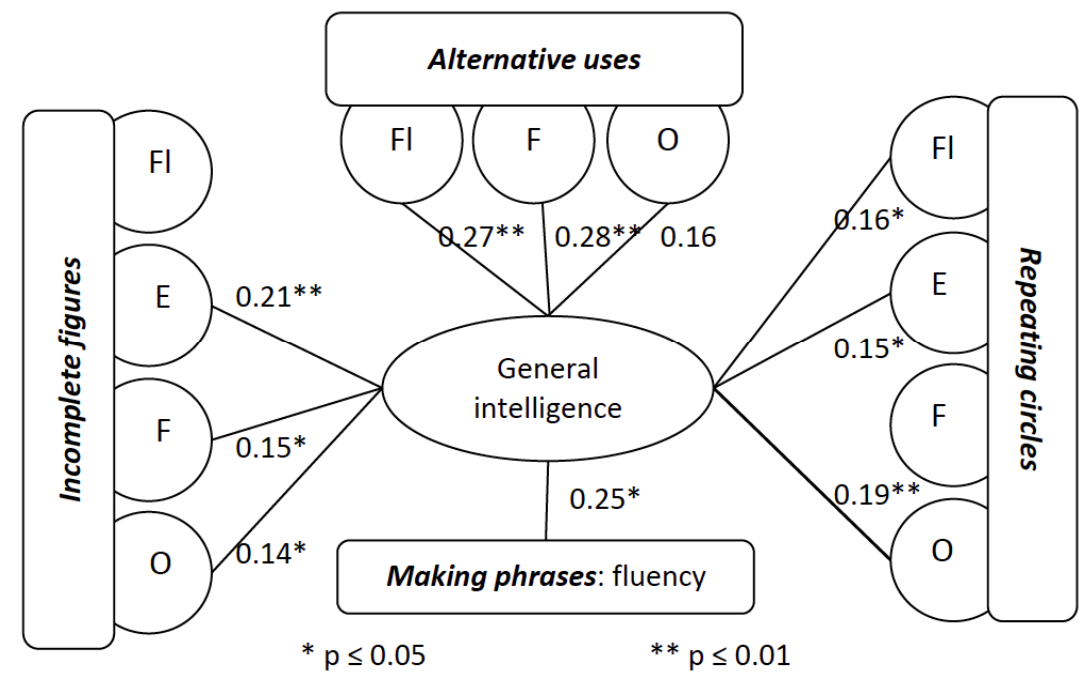

Figure 1: The structure of the correlation between the indicators of creative tests and intelligence among students of the Faculty of Physical Education, $\mathrm{N}=224$ ( $\mathrm{FI}$ - fluency, $\mathrm{F}$ - flexibility, $\mathrm{O}$ - originality, $\mathrm{E}$ - elaboration).

Table 2: Clusters of Students with a Different Combination of Creativity and Intelligence, the Corresponding Average Indicators of Sociometric Statuses

\begin{tabular}{|c|c|c|c|c|}
\hline \multirow[t]{2}{*}{ The Cluster's description } & \multirow{2}{*}{$\begin{array}{l}\text { Proportion of } \\
\text { the sample, } \%\end{array}$} & \multicolumn{3}{|c|}{ Sociometric choice criteria: } \\
\hline & & academic & $\begin{array}{l}\text { informally } \\
\text { emotional }\end{array}$ & $\begin{array}{l}\text { sports } \\
\text { team }\end{array}$ \\
\hline $\begin{array}{l}\text { Cluster 1. Gifted - have a high or above medium indicator of general } \\
\text { intelligence, which is combined with high or above-average indicators of all } \\
\text { creativity subtests. }\end{array}$ & $3 \%$ & 0.64 & 0.44 & 0.32 \\
\hline $\begin{array}{l}\text { Cluster 2. Intellectuals with pronounced verbal creativity (high productivity of } \\
\text { the test "Making phrases"). }\end{array}$ & $15 \%$ & 0.49 & 0.55 & 0.35 \\
\hline $\begin{array}{l}\text { Cluster } 3 \text {. Intellectuals with a medium or lower than the medium level of } \\
\text { creativity for all tasks (the reverse picture - when a high level of creativity is } \\
\text { accompanied by reduced intellectual indicators was not found in the sample). }\end{array}$ & $9 \%$ & 0.44 & 0.25 & 0.15 \\
\hline $\begin{array}{l}\text { Cluster } 4 \text {. Students with high rates of fluency and originality in the test } \\
\text { "Alternative uses", which is accompanied by a medium or lower than the } \\
\text { medium level of intelligence. }\end{array}$ & $15 \%$ & 0.35 & 0.47 & 0.46 \\
\hline $\begin{array}{l}\text { Cluster } 5 . \text { Imaginative creativity as a leading quality (implies a partial } \\
\text { decrease in a verbal and medium level of intellectual abilities). }\end{array}$ & $10 \%$ & 0.21 & 0.12 & 0.07 \\
\hline Cluster 6. The medium level of cognitive abilities for all tests. & $34 \%$ & 0.39 & 0.33 & 0.37 \\
\hline $\begin{array}{c}\text { Cluster } 7 . \text { Low and below-average indicators for tests of intellectual and } \\
\text { creative abilities. }\end{array}$ & $5 \%$ & 0.05 & 0.24 & 0.11 \\
\hline Cluster 8 . The uneven development of creativity. & $9 \%$ & 0.25 & 0.29 & 0.18 \\
\hline
\end{tabular}

Table 3: Average Indicators of Sociometric Statuses in Clusters with a Different Combination of Cognitive Abilities

\begin{tabular}{|c|c|c|c|c|}
\hline & \multirow{2}{*}{$\begin{array}{l}\text { Size and proportion of the } \\
\text { sample }\end{array}$} & \multicolumn{3}{|c|}{ Sociometric choice criteria: } \\
\hline & & academic & informally emotional & sports team \\
\hline Cluster 1 & 7 people, $3 \%$ & 0.64 & 0.44 & 0.32 \\
\hline Cluster 2 & 34 people, $15 \%$ & 0.49 & 0.55 & 0.35 \\
\hline Cluster 3 & 20 people, $9 \%$ & 0.44 & 0.25 & 0.15 \\
\hline Cluster 4 & 34 people, $15 \%$ & 0.35 & 0.47 & 0.46 \\
\hline Cluster 5 & 22 people, $10 \%$ & 0.21 & 0.12 & 0.07 \\
\hline Cluster 6 & 76 people, $34 \%$ & 0.39 & 0.33 & 0.37 \\
\hline Cluster 7 & 11 people, $5 \%$ & 0.05 & 0.24 & 0.11 \\
\hline Cluster 8 & 20 people,9 \% & 0.25 & 0.29 & 0.18 \\
\hline
\end{tabular}


Table 4: Frequency of Distribution of the Scores of General Intelligence (Percentile Norms) in Respondents with Different Levels of Sociometric Status

\begin{tabular}{|c|c|c|c|c|}
\hline \multirow{2}{*}{$\begin{array}{c}\text { General intelligence } \\
\text { (percentile norms) }\end{array}$} & \multicolumn{4}{|c|}{ Sociometric status } \\
\cline { 2 - 5 } & Leaders & Popular & Semi-popular & 0.9 \\
\hline 95 & 16 & 13.6 & 2.8 & - \\
\hline 90 & 24 & 29.5 & 70.1 & 17.8 \\
\hline 75 & 52 & 45.5 & 11.4 & 80.0 \\
\hline 50 & 8 & - & 45.8 & 4.2 \\
\hline
\end{tabular}

The Relationship of Cognitive Abilities and Position in Interpersonal Relationships

Sociometric status is unevenly distributed among people; there are always "stars" and rejected members in each social group. According to the results of processing three sociometric samples, we divided the subjects into sub-samples depending on intra-group credibility: group leaders $(\mathrm{N}=25)$, popular $(\mathrm{N}=44)$, semi-popular $(N=107)$ and isolated $(N=48)$. The percentage of isolation is especially high at the beginning of training (freshmen make up $46 \%$ of the group of isolated people), which reflects the natural dynamics of intragroup interaction.

In each group, the number of students with different ability levels was calculated and the corresponding share in the subsample was calculated - Table 4 and Figure 2.

We see that students with high social status have a high and above-average level of intellectual development (among the leaders and popular members of the group there is not a single person with
Verbal Creativity "Making Phrases"

- low level $\square$ middle level $\quad$ high level

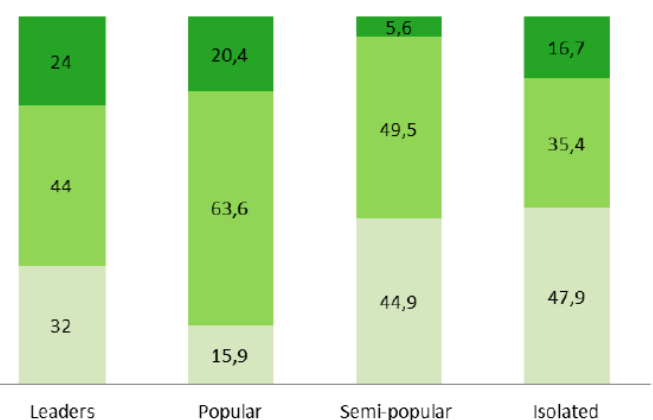

Creativity “Alternative Uses Task”

Gow level middle level a high level

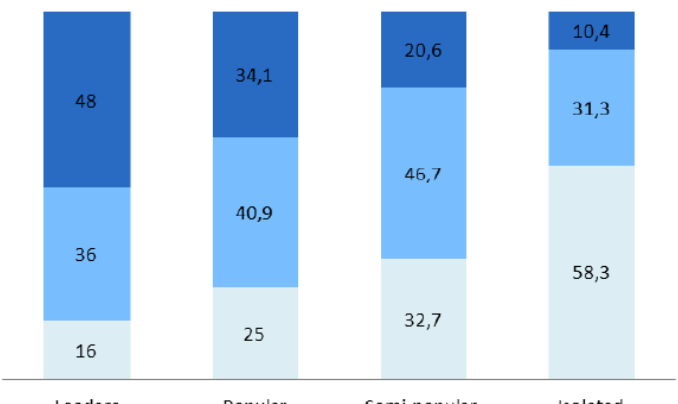

Leaders

Isolated

Imaginative creativity "Incomplete figures" +

"Repeating circles"

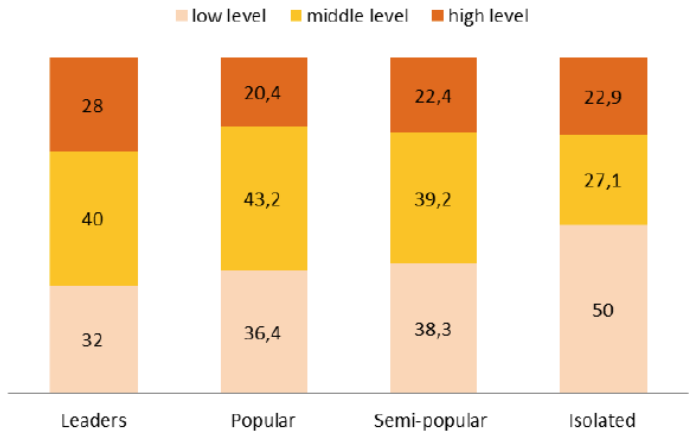

Figure 2: Frequency of distribution of the results of completing creative tasks (level according to intragroup standards) in respondents with different sociometric status. 
Table 5: Correlations between the Sociometric Status of Students and Indicators of Cognitive Abilities ( $\mathrm{N}=224$ )

\begin{tabular}{|c|c|c|c|}
\hline \multirow{2}{*}{ Measurement of cognitive abilities } & \multicolumn{3}{|c|}{ Sociometric choice criteria: } \\
\hline & academic & informally emotional & sports team \\
\hline $\begin{array}{l}\text { General intelligence } \\
\qquad \text { Raven's progressive matrices }\end{array}$ & $0.356^{\star *}$ & $0.146^{*}$ & $0.240^{* *}$ \\
\hline Non-verbal (imaginative) creativity & & & \\
\hline $\begin{array}{l}\text { "Incomplete figures": } \\
\qquad \begin{array}{l}\text { fluency } \\
\text { flexibility } \\
\text { originality } \\
\text { elaboration }\end{array}\end{array}$ & $\begin{array}{c}0.011 \\
0.004 \\
-0.013 \\
0.009\end{array}$ & $\begin{array}{l}-0.073 \\
-0.006 \\
-0.123 \\
-0.065\end{array}$ & $\begin{array}{r}0.079 \\
0.010 \\
-0.111 \\
-0.004\end{array}$ \\
\hline $\begin{array}{l}\text { Repeating circles } \\
\qquad \begin{array}{l}\text { fluency } \\
\text { flexibility } \\
\text { originality } \\
\text { elaboration }\end{array}\end{array}$ & $\begin{array}{l}0.098 \\
0.051 \\
0.005 \\
0.026\end{array}$ & $\begin{array}{l}-0.003 \\
-0.012 \\
-0.047 \\
-0.051\end{array}$ & $\begin{array}{c}0.088 \\
0.017 \\
-0.015 \\
0.022\end{array}$ \\
\hline Verbal creativity & & & \\
\hline $\begin{array}{l}\text { fluency } \\
\text { flexibility } \\
\text { originality }\end{array}$ & $\begin{array}{l}0.148^{*} \\
0.153^{*} \\
0.140^{*}\end{array}$ & $\begin{array}{l}0.145^{\star} \\
0.155^{\star} \\
0.125\end{array}$ & $\begin{array}{c}0.188^{* *} \\
0.172^{*} \\
0.135\end{array}$ \\
\hline Making Phrases & 0.031 & 0.071 & $0.142^{*}$ \\
\hline
\end{tabular}

Note: ${ }^{*} p \leq 0.05 ;{ }^{*} p \leq 0.01$

an intelligence level below average). At the same time, among the leaders, there are students with both high and low levels of creativity. The result of the Alternative Uses Task is more closely related to social authority than others - $48 \%$ of leaders demonstrate high productivity and resourcefulness (we saw earlier that this indicator strongly correlates with general intelligence).

In the group of isolated students, there is a small percentage (from 10.4 to $22.9 \%$ ) of students with high scores for creativity tests. But a much larger part of this group (from 47.9 to $58.3 \%$ ) demonstrates low productivity in situations requiring creative solutions.

Special attention is paid to indicators of verbal creativity. The word is an instrument of interpersonal communication; the greater the mastery of the word in a person, the easier it is for him/her to take a leading position. There were six people in the sample with extremely high results of the "Making phrases" task three of them were included in the category of leaders, and three were in the category of "isolated". This shows the non-linear nature of the relationship.

We specify the obtained dependences using correlation analysis. Table $\mathbf{5}$ shows the Pearson correlation coefficients calculated over the entire sample with respect to sociometric status in various aspects of interpersonal relationships.

The data obtained confirm that there is a strong direct relationship between the level of intellectual development and sociometric status in the student group.

Regarding creative abilities, the data is ambiguous. Imaginative creativity demonstrates negative but weak correlations with social authority in various fields. Verbal productivity (making phrases) turned out to be significantly related to the choice of a group member as the leader of a sports team, but it weakly correlates with the academic and informally emotional sphere of relations (we have previously shown the non-linear nature of data distribution). The results of the "Alternative Uses" test show several positive correlations with the sociometric status of a group member, which confirms the special status of this type of creative abilities.

\section{DISCUSSION}

In achieving this goal - to find out the features of the formation of creativity and intelligence of student- 
athletes in connection with their position in interpersonal relationships, we obtained important empirical results, confirmed by data from previous scientists.

1. First of all, our study demonstrated the dynamics of the formation of creativity and intelligence in the learning process.

Studying at the university, students gain a diverse cognitive experience, which undoubtedly affects the growth of indicators of intellectual and creative abilities. At the same time, the dynamics of increasing intelligence indicators during the transition to the next year of study is quite stable, and the results of performing creative tasks are uneven. In the first year, most indicators of creativity are decreased, which is most likely due to adaptation to a new social role, the rules of a higher educational institution. B. Barbot [16] confirms the deterrent effect of the social environment on the development of creativity. Indeed, adaptation to the social context implies the fulfilment of regulatory requirements and natural conformism as a mechanism for adapting to a new group, which suppresses the manifestations of originality (both in behaviour and in creativity tests).

In the year of graduation, the productivity of generating ideas grow, but their flexibility and originality decrease. This can be explained by saving cognitive efforts with intense adaptation to the academic workload (defence of diploma and exams). It should be borne in mind that achievements in creative tasks depend not only on cognitive efforts and abilities but also on personal factors [35]. It is known that creativity is a central component of identity formation in adolescence: it stimulates thought processes, supports a positive image of oneself, and promotes selfexpression [36]. This to some extent explains the age peaks and declines in the dynamics of creative abilities.

2. Secondly, the results showed a variety of manifestations of cognitive abilities of students. Taxonomic groups are singled out that reflect the real existing strategies of cognitive activity of sportsmen students. The results of the sampling did not reveal a combination of high levels of creativity with reduced intelligence, which confirms the theory of the intellectual threshold described in the theoretical background $[1,4$, 19].

Clustering students revealed a rather large typological segment (15\% of respondents) with high productivity and quality of ideas for the alternative use of objects in everyday life. It reflects a separate type of abilities that is important in social adaptation - practical creativity. That is, the "Alternative Uses" task, although formally related to verbal subtests, actually diagnoses not the ability to operate with words and meanings, but everyday survival skill - practical, everyday resourcefulness (expressed in verbal form). This conclusion is confirmed by the obtained correlations with the general intelligence and sociometric status of students. In the early studies of E. Tunik [20], the results of the "Alternative Uses" task also closely correlated with the parameters of social adaptation, in contrast to other verbal creativity tests.

All this allows asserting that the phenomenon of daily creativity underlies the estimates obtained. At the time of the creation and testing of the method, this concept did not exist yet. But in recent years, many scholars have focused on Everyday Creativity: "human originality at work and leisure across the diverse activities of everyday life," which is common to everyone and underlies adaptation to change [7]. The Alternative Uses task is a long-known and convenient tool for measuring this ability.

A variety of individual structures provides effective adaptation mechanisms in different conditions of life (for example, a combination of intellectual abilities and verbal creativity ensures success in business and interpersonal communication). The data obtained should be considered in a wider context: according to a multidimensional approach, creativity is the result of a combination of psychological properties (cognitive, motivational, emotional) and stimulating/depressing environmental factors. Multiple combinations of these components explain a wide range of individual differences [37]. Modern studies in different countries of the world confirm that the correlation between creativity and intelligence is a powerful predictor of educational and professional achievements [5, 38]. The individual structure of abilities should be taken into account in the organization of educational activities of students.

It should be noted that a variety of cognitive strategies is a necessary condition for the survival of a group, organization, society as a whole.

\section{Cognitive Abilities as a Factor in Building Interpersonal Relationships}

When studying sociometric statuses, a large number of students fell into the category of "isolated" - 
48 people, which is $21.4 \%$ of the sample. Especially often freshmen fall into this position. On the one hand, this reflects the natural dynamics of relations at the beginning of group formation, and on the other hand, it requires focused work to improve communication and interaction of students in educational activities.

According to Ya. L. Kolominsky [39], sociometric status is a stable value; it often "goes" into a new group together with a person. Social authority is influenced not only by intelligence, but also by appearance, temperament, and also success in activities that are significant for members of this group. The data obtained allow expanding this view and consider creativity as a resource of interpersonal interaction, which manifests itself in very specific conditions - in case of uncertainty and instability of the situation.

Cognitive abilities play an important role in the social behaviour of students: the formation of popularity is directly affected by intelligence and practical creativity (in this study, other factors of interpersonal attraction, such as goodwill, emotionality, extraversion, etc. were not established). Verbal creativity is associated with success in interpersonal relationships, but this relation is non-linear. Highly creative students can have both high and low social status. In this regard, we turn to the concept of over-adaptive creativity that goes beyond social needs and impedes harmonious interpersonal relationships.

Creativity, by definition, involves going beyond existing social norms and traditions. Several scholars in different countries raise the question that the socialization of creative individuals is difficult due to several psychological characteristics. E. A. Veldbrecht [40] empirically substantiated the model of creativity optimum as a factor in socio-psychological adaptation: the difficulties of low-creative individuals are caused by the inability to respond to changing environmental requirements; and the disadaptation of creatives is explained by specific personal characteristics (autonomy, non-conformism, dominance, emotional instability, etc.). F. Gino and D. Ariely [41] writes about The Dark Side of Creativity, focusing on vicious creativity, and the relationship between creativity and dishonest, unethical behaviour.

It is appropriate to recall an established opinion about the connection of creative manifestations with personality functioning disorders and even mental disorders [20, 26, 42]. S. Carson [463] describes this relationship using a model of shared biological vulnerability. Genetic vulnerability factors include access to altered states of consciousness: cognitive disinhibition, novelty-driven attention style, associations between disparate incentives, etc. These features can manifest themselves as psychopathology (mood disorders, schizophrenia spectrum disorder, alcoholism), or as creative abilities, depending on the availability of protective factors in the form of cognitive abilities. High IQ, capacious memory, and cognitive flexibility expand the range of conscious stimuli to form new and original ideas [43].

A. Voronin [44] offers a new understanding of intelligence and creativity as a joint activity in the course of solving a real problem or situation. The participants in a joint intellectual process are united by a common goal, which can be realized in various ways: using knowledge (learning ability), finding an unobvious solution (intelligence), creating a new one (creativity). At different stages of joint activity, each participant performs specific tasks according to their abilities and personal characteristics: initiation, declaration of goals, setting goals, collecting information, finding solutions, their implementation, improvement, evaluation. This involves the distribution of social roles between participants (initiator, expert, generator of ideas, critic, cultivator, etc.). An important characteristic of joint intellectual activity is its modification depending on the structure of interpersonal relationships. "Dominant" participants determine the beginning, end and pace of interactions, the alternation of stages and their content [44]. At a subjective level, participation in the joint intellectual activity is understood as the acquisition of cognitive experience and overcoming one's own inability. It is quite clear that such experience leads to increased competence, the development of intellectual skills, and the growth of creativity. The possibility of reducing the level of creativity and/or intelligence is less evident but likely - this happens, for example, when the personality characteristics of the lecturer and students do not coincide, as empirically proved by A. Voronin and I. Trifonova [44]. This concept allows introducing the characteristics of interpersonal interaction into the analysis of cognitive functions and explains why all the leaders in the student environment demonstrated intelligence at a level above average or high.

\section{The Influence of Sports and Physical Training on the Results}

The results obtained should be carefully applied to students of other specialities. There is data on a 
decrease in creativity and intellectual abilities of students by the end of the study, which contradicts our results. E. Sola [45] showed that the level of creativity of bachelors - engineers at the beginning of the study is higher than at the end, while the level of critical thinking does not increase. S. Atwood and J. Pretz [46] argue that creativity is not properly encouraged in industryspecific curricula, and creative students are less likely to graduate.

It is important to understand that the educational and professional specifics of sportsmen students are determined by the factor of physical activity, which is reflected in the characteristics of psychological regulation. A study by $E$. Bulich [47] convincingly proved that regular exercise stimulates mental performance and increases psycho-emotional resistance to stress. V. Markelov [48] found that sports activity is associated with the preference of rational coping models in difficult situations; it is a factor of selforganization and integration of students' individuality.

On the other hand, reputable scholars write that intelligence is determined not so much by the mechanisms of information processing but by the regulation of available intellectual resources [49]. $R$. Sternberg [50] explained the dialectical relation between creativity, intelligence and wisdom: intelligence is usually used to promote existing ideas and values, while creativity most often violates the existing order of things and proposes a new one. Wisdom is to achieve a balance between intelligence and creativity (old and new), which allows harmonizing stability and variability in a social context.

Thus, regular physical activity, strengthening the body's self-regulatory resources contributes to intellectual efficiency, which in turn ensures the harmonization of creative manifestations. In a situation of intense adaptation, sportsmen students redistribute cognitive efforts, directing them to more relevant and priority tasks. The results and conclusions obtained are of general theoretical significance since optimal physical activity opens up wide opportunities for increasing the psychological well-being of a person, including cognitive improvement.

\section{CONCLUSION}

The results of a study of students of different years showed that in a situation of increased workload and stress, a balanced redistribution of cognitive resources occurs: saving in some tasks allows you to direct "mental forces" to an effective solution of others. The leading role in social adaptation is played by intellectual abilities and verbal skills; at the same time, the authority in interpersonal interaction depends on the needs of the group and actual needs of the life situation. A wide variety of individual combinations of abilities with a predominance of certain cognitive qualities (intelligence, imaginative, verbal or practical creativity) should be used so that each student takes a favourable social position in the group. Being a source of useful ideas in unstable, crisis and uncertain situations, creativity is a resource of interpersonal interaction in a group. In developing the abilities of students of the Faculty of Physical Education, special attention should be paid to expanding verbal opportunities, as well as to the skills of practical creativity in everyday life.

\section{ACKNOWLEDGEMENT}

No one gave the contribution to this research and also there wasn't any granting agency.

\section{REFERENCES}

[1] Guilford JP. Creativity. American Psychologist 1950; 5(9): 444 54 https://doi.org/10.1037/h0063487

[2] Bogoyavlenskaya DB. Psychology of Creative Abilities. Samara: Fedorov 2009.

[3] Ponomarev YA. Psychology of Creativity. Moscow: Nauka 1976.

[4] Barron F, Harrington D. Creativity, Intelligence, and Personality. Annual Review of Psychology 1981; 32: 439-76. https://doi.org/10.1146/annurev.ps.32.020181.002255

[5] Furnham A. The Relationship between Cognitive Ability, Emotional Intelligence and Creativity. Psychology 2016; 7: 19397.

https://doi.org/10.4236/psych.2016.72021

[6] Sternberg RJ. The nature of creativity. Creativity Research Journal 2006; 18: 87-98.

https://doi.org/10.1207/s15326934cri1801 10

[7] Richards R. Everyday creativity and new views of human nature: Psychological, social, and spiritual perspectives. Washington, DC: American Psychological Association 2007. https://doi.org/10.1037/11595-000

[8] Kaufman JC, Beghetto RA. Beyond Big and Little: The Four C Model of Creativity. Review of General Psychology 2009; 13: 112.

https://doi.org/10.1037/a0013688

[9] Matyushkin AM. Puzzles of Endowment: Problems of Practical Diagnostics. Moscow: Direct Media 2014.

[10] Renzulli JS. Developing Creativity Across All Areas of the Curriculum. In: Beghetto RA, Kaufman, JC, editors, Nurturing creativity in the classroom, Chapter: 5. New York: Cambridge University Press 2017; pp. 23-44. https://doi.org/10.1017/9781316212899.006

[11] Wallach MA, Kogan N. A new look at the creativity-intelligence distinction. Personality 1965; 33(3): 348-69. https://doi.org/10.1111/j.1467-6494.1965.tb01391.x

[12] Simonton DK. Origins of Genius: Darwinian Perspectives on Creativity. New York: Oxford Univ. Press 1999.

[13] Martinsen OL. The creative person: A synthesis and development of the creative person profile. Creativity Research Journal 2011; 23: 185-202.

https://doi.org/10.1080/10400419.2011.595656 
[14] Feldman DY, Csikszentmihalyi M, Gardner H. Changing the world: A framework for the study of creativity. Yale: Yale Press 1994.

[15] Voronin AN. Intellectual Activity: A Manifestation of Intelligence and Creativity in Real Interaction. Psychology. Journal of the Higher School of Economics 2006; 3(3): 35-58.

[16] Barbot B. Structures identitaires et expression créative à l'adolescence. L'Orientation scolaire et professionnelle 2008; 37(4): 483-507.

https://doi.org/10.4000/osp.1772

[17] Mednick SA. The associative basis of the creative process. Psychological Review 1962; 69(3): 220-32. https://doi.org/10.1037/h0048850

[18] Guilford JP, Hoepfner R. The Analysis of intelligence. New York: McGraw-Hill Book Co. 1971.

[19] Torrance EP. The nature of creativity as manifest in its testing. In: Sternberg RJ, editor, The nature of creativity: Contemporary psychological perspectives. New York: Cambridge University Press 1988; 43-75.

[20] Tunik EE. Diagnostics of Creativity. Test of E. Torrens. Adapted Version. St. Petersburg: Rech 2006.

[21] Hennessey BA. Developing Creativity in Gifted Children: The Central Importance of Motivation and Classroom Climate. Storrs: Natl. Res. Cent. Gifted Talented 2004.

[22] Starko AJ. Creativity in the Classroom Schools of Curious Delight. New York: Routledge 2014. https://doi.org/10.4324/9780203115176

[23] Mumford MD. Handbook of Organizational Creativity. London: Academic Press 2012.

[24] Amabile TM. Creativity in Context. Boulder: Westview Press 1996.

[25] Hennessey BA, Amabile TM. Creativity. Annu Rev Psychol 2010; 61: $569-98$.

https://doi.org/10.1146/annurev.psych.093008.100416

[26] Druzhinina SV. Correlation of Intellectual Abilities and Creativity in the Structure of Intelligence. Acmeology 2016; 1: 89-93.

[27] Zolotovitsky RA. Organizational Art Therapy and Training: SocioDrama and Sociometry in Working with Organizations. Moscow: Moreno Institute 2003.

[28] Raven J. The Raven's Progressive Matrices: Change and Stability over Culture and Time. Cognitive Psychology 2000; 41(1): 1-48.

https://doi.org/10.1006/cogp.1999.0735

[29] Raven JK, Cort JH, Raven J. A Guide to Raven's Progressive Matrices and Vocabulary Scales. Section 3. Standard Progressive Matrices (including Parallel and Plus Versions). Moscow: Kogito-Center 2012.

[30] Davydov DG, Chmykhova EV., Application of the Test Raven's Standard Progressive Matrices with a Time Limit. Voprosy Psychologii 2016; 4: 129-139.

[31] Druzhinin VN. Psychology of General Abilities. St. Petersburg: Peter 1999

[32] Veldbrekht EA. Diagnostics of Creative Abilities. Kherson: KhDPU Publishing House 2002.

[33] Briggs RO, Reinig BA. Bounded Ideation Theory. Journal of Management Information Systems 2010; 27(1): 123-44. https://doi.org/10.2753/MIS0742-1222270106

[34] Batey M, Furnham A, Safiullina X. Intelligence, general knowledge and personality as predictors of creativity. Learning and Individual Differences 2010; 20(5): 532-35. https://doi.org/10.1016/j.lindif.2010.04.008
[35] Barbot B, Lubart T. Adolescence, créativité et transformation de Soi. Enfance 2012; 3(3): 299-312. https://doi.org/10.4074/S0013754512003059

[36] Lubart TI. Componential models of creativity. In: Runco MA Pritzer S, editors, Encyclopedia of creativity. New York: Academic Press 1999; pp. 295-300.

[37] Novakov I. Cognitive and personological determinants of creativity indicators in students. Journal of Education 2018; 67(3): 419-438. https://doi.org/10.5937/nasvas1803419N

[38] Shi B, Wang L, Yang J, Zhang M, Xu L. Relationship between divergent thinking and intelligence: An empirical study of the threshold hypothesis with Chinese children. Frontiers in Psychology 2017; 8: 254. https://doi.org/10.3389/fpsyg.2017.00254

[39] Kolominsky YL. Social Psychology of Relationships in Smal Groups. Moscow: AST 2010.

[40] Veldbrekht OO. A Model of the Creativity Optimum as the Ability of Social and Psychological Adaptation. Practical Psychology and Social Work 2009; 8: 15-20.

[41] Gino F, Ariely D. The Dark Side of Creativity: Original Thinkers Can Be More Dishonest. Journal of Personality and Social Psychology 2012; 3: 445-459 https://doi.org/10.1037/a0026406

[42] Kaufman JC. The Sylvia Plath effect: Mental illness in eminent creative writers. Journal of Creative Behavior 2001; 35(1): 37-50. https://doi.org/10.1002/j.2162-6057.2001.tb01220.x

[43] Carson SH. Creativity and Psychopathology: A Shared Vulnerability Model. Canadian Journal of Psychiatry 2011; 56(3): 144-153. https://doi.org/10.1177/070674371105600304

[44] Voronin AN, Trifonova IG. The Influence of Similarity/Contrast of the Personality Characteristics of the Teacher and Student on the Change in the Level of Various Components of Student Creativity. Psychological Journal 2002; 6: 15-27.

[45] Sola E, Hoekstra R, Fiore S, McCauley P. An Investigation of the State of Creativity and Critical Thinking in Engineering Undergraduates. Creative Education 2017; 8: 1495-1522. https://doi.org/10.4236/ce.2017.89105

[46] Atwood SA, Pretz JE. Creativity as a Factor in Persistence and Academic Achievement of Engineering Undergraduates. Journal of Engineering Education 2016; 105(4): 540-559. https://doi.org/10.1002/jee.20130

[47] Bulich EV. Physiological and Hygienic Characteristics of the Impact of Physical Education on Mental Performance and Psycho-Emotional Stability of Students. Scientific Notes of SGU 1997; 4: 23-27.

[48] Markelov VV. Sports Activity as a Factor of Integration of Properties in the Structure of Individuality of Students. Bulletin of the Perm State Humanitarian and Pedagogical University. Series No. 1. Psychological and Pedagogical Sciences 2016; 2(1): 6-9

[49] Kholodnaya MA. Psychology of Intelligence: The Paradoxes of Research. St. Petersburg: Peter 2001.

[50] Sternberg RJ. What is the common thread of creativity? Its dialectical relation to intelligence and wisdom. American Psychologist 2001; 56: 360-362. https://doi.org/10.1037/0003-066X.56.4.360

\section{DOI: https://doi.org/10.6000/2292-2598.2019.07.03.17}

(c) 2019 Yakymchuk et al.; Licensee Lifescience Global.

This is an open access article licensed under the terms of the Creative Commons Attribution Non-Commercial License (http://creativecommons.org/licenses/by-nc/3.0/) which permits unrestricted, non-commercial use, distribution and reproduction in any medium, provided the work is properly cited. 